\title{
Aquatic invaders: from success factors to ecological risk assessment: introduction
}

\author{
Gerard van der Velde · Rob S. E. W. Leuven • \\ Rob J. Leewis · Abraham bij de Vaate
}

Published online: 25 June 2009

(C) The Author(s) 2009. This article is published with open access at Springerlink.com

The International Conference on Aquatic Invasive Species (ICAIS) began as a Canada/USA initiative, with its genesis as a conference to address the appearance of zebra mussels in the Great Lakes in the 1980s. By the late 1990s the conference began to address other non-indigenous aquatic invasive species (AIS) and it continued to evolve to incorporate new and emerging AIS issues.

The conference currently functions as the most comprehensive international forum for the review of accumulated scientific knowledge, the presentation of

\section{G. van der Velde $(\bowtie)$}

Department of Animal Ecology and Ecophysiology, Institute for Water and Wetland Research, Radboud University Nijmegen, Heyendaalseweg 135, 6525 AJ Nijmegen, The Netherlands

e-mail: g.vandervelde@science.ru.nl

\section{R. S. E. W. Leuven}

Department of Environmental Sciences, Institute for Water and Wetland Research, Radboud University

Nijmegen, Heyendaalseweg 135, 6525 AJ Nijmegen, The Netherlands

e-mail: r.leuven@science.ru.nl

\section{R. J. Leewis}

Kloosterwei 12, 2361 XL Warmond, The Netherlands e-mail: r.leewis@casema.nl

\section{A. bij de Vaate}

Waterfauna Hydrobiologisch Adviesbureau, Oostrandpark 30, 8212 AP Lelystad, The Netherlands

e-mail: vaate@waterfauna.nl the latest field research, the introduction of new technological developments for prevention, monitoring and control and discussion of policy, legislation, public education and outreach initiatives to raise awareness of the impacts of aquatic invasive species and prevent new introductions. The 15th ICAIS was held in Nijmegen, The Netherlands, September 23-27, 2007. This conference was the second one organized in Europe.

Selected contributions of the 12th ICAIS (Windsor, Ontario, Canada, June 9-12, 2003) were published in an earlier special issue of Biological Invasions (vol. 8, number 1, 2006). As a guest editor Elizabeth Muckle-Jeffs wrote in that issue: "It is our hope that they serve as a record of the ongoing effort by the participants of the conference to bring the problem of aquatic invasive species to the attention of policy makers and the general public".

Since then biological invasions are increasingly important, influencing ecosystems all over the world. The present special issue of Biological Invasions contains selected papers from the Nijmegen conference reflecting the progress in understanding biological invasions including new approaches. The issue starts with a paper on the Rhine River as a global highway for invaders followed by a paper on traits of all invasive aquatic macroinvertebrate species in North America and Europe. A series of papers devoted to amphipod invaders follows. Amphipods belong to the most successful invaders and are-because of their species richness, abundance, size and omnivorous 
diet—ideally suited for biomonitoring, for studying species replacements, and for field and laboratory experiments testing invasion theories. Their invasion processes have been studied in detail and hypotheses are underpinned by experimental research.

One paper deals on tracing the origin of the invasion by the zebra mussel in Spain using Amplified Fragment Length Polymorphism (AFLP). Two other papers are on fish, one on the diet of an invasive goby and one on the pumpkinseed sunfish in Europe. The last papers demonstrate another trend in invasion studies, viz. to carry out the studies over large areas to find trends in invasiveness, life history traits and genetics over latitudinal and longitudinal gradients. All approaches of the studies presented in this special issue are complementary and provide us with information on a different scale about invasion processes.

This knowledge is essential to sound ecological risk assessments and effective management of AIS.

Open Access This article is distributed under the terms of the Creative Commons Attribution Noncommercial License which permits any noncommercial use, distribution, and reproduction in any medium, provided the original author(s) and source are credited.

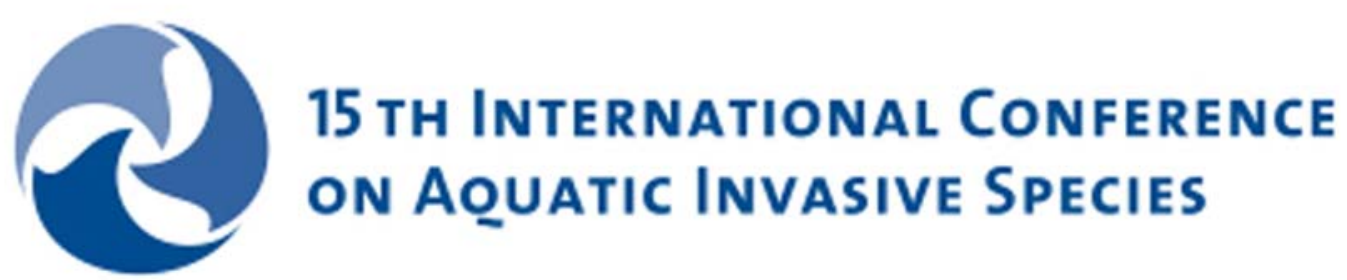

$\begin{array}{lllll}2 & 0 & 0 & 7\end{array}$ 